ation. Curettage was done at the time the patients were treated. Many of them had been curetted previously but unsuccessfuily, or they would not have come into our hands for treatment for the hemorrhage. It is an entire innovation in our methods and in the matter of the benefit of the patient. The operative cures of sarcomas of the uterus are practically nil. In about 400 cases treated with radium and Roentgen rays in Freiburg there is no case on record with history of subsequent development of malignancy. In illustration as to the effect in sarcomas: A tall overgrown lad with a big tumor in the left abdomen comes for treatment. After treatment for several months, on examination nothing could be felt through the abdomen but a small mass through the rectum. Dr. Burnam took that out and it was found to be a testicle which had become sarcomatous. On the other side there were two fallopian tubes and a little uterus in between. In other words, it was a case of mixed sex elements. Something new has come into our midst and something big. We must take hold of it and see what comes of it. We are using radium every day for uterine hemorrhage, for fibroid uteri. We have radiated many carcinomas of the cervix uteri. In some cases we have later removed the uterus. In not one have we discovered any cancerous elements remaining. In one of them we found some of the pelvic lymphatic glands infected. In one case we found the glands enlarged at the operation. We have a very definite hope that we can follow these cases in a considerable series. A number of cases come to us with other ailments, such as Bright's disease, diabetes and carcinoma of the uterus, which cannot be operated on. Some have profound anemia; others tuberculosis. To all these cases radium comes as a great boon, which is going to be extended and which we hope to develop in this class of cases. It does not take such a large amount of radium that the siender pocketbook cannot afford it.

Dr. George E. Pfahler, Philadelphia: I want only to answer one or two points, one with reference to the disappearance of the tumor. I said that 75 per cent. of the tumors I had treated had disappeared, and so they have, and you must not forget that these quotations made by Dr. McGlinn are mostly based on the work of men of few years of experience. They have treated more cases than I have. The roentgenologists have been working for from eight to ten years, and that is the reason we can. speak with a little greater emphasis than these men can, because the tumor continues to disappear long after the treatment has stopped. With reference to degeneration of the tumor, I inquired of the physician who treated the patient referred to by Dr. Shoemaker. The patient came weekly for treatment through the years when the treatment was much less developed than at present. He referred the patient for operation. Regarding degeneration of these tumors, it has been stated by men who know that 5 per cent. undergo malignant degeneration. If this is true, why have not 5 per cent. of those treated undergone degeneration? And if they have, do you believe that the physicians of this country have so neglected their duty that they will not call the attention of the profession to the fact that these tumors undergo degeneration later? Until we have definite data we have no right to assume that these tumors will undergo subsequent degeneration.

Insects and Disease.-When the history of medicine during the past quarter of a century comes to be written, the one outstanding feature of the period will be shown to be "the part played by insects in the spread of disease," and the application of this knowledge as a practical hygienic factor. Vermin have been "detested, shunned by saint and sinner," since the creation of man, but the reason for the abhorrence has only been proved of late years. That the mosquito can carry malaria, yellow fever and filaria; and that the bedbug, the louse, the flea, the fly, the blackbeetle, the tick, the itch insect and other vermin are agents in the transmission of a given disease is now common knowledge. This information has placed the subject of domestic and public hygiene and sanitary endeavor on a sure foundation, and given a stability to preventive measures hitherto unattainable.-Jour. Trop. Med. and Hyg., April 15, 1914.

\title{
AN UNUSUAL CASE OF BROMODERMA OF THE LEG*
}

LUDWIG WEISS, M.D.

Consulting Dermatologist Hebrew Orphan Asylum, Saint Mark's and People's Hospital, Chief of Clinic of Genito-Urinary and Dermatological Department, German Poliklinik

\section{NEW YORK}

Of the three halogen elements which play such a great role in the household of nature, bromin, discovered by Bayard in 1826, is the youngest. The others are iodin, discovered by Schele in 1774, and chlorin by Curtois, in 1812. English and French physicians were the first to use bromin and to study its action. $^{1}$ In Germany Otto Graf (1840) emphasized its sedative and depressant action on the nerve-centers. But it remained for Sir Charles Locock to introduce it in 1851, and to acquaint the profession with its main therapeutic virtues. Its position at present is that of a neuromuscular depressant and as such its main use, logically, is directed against the best-known of all con-

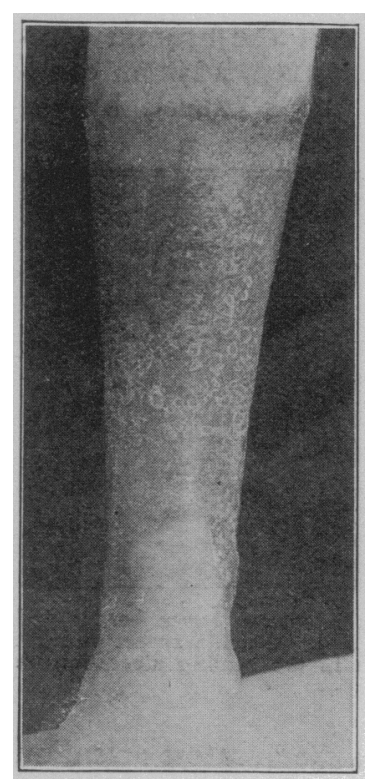

Fig. 1.-Bromoderma of leg; showing a slightly scalloped border with a few partly healed ulcerations. Lower border ends abruptly in a semi-circular line. in a semi-circular line.
Quiescent stage. No active symptoms at present. Leg shows smooth atrophic surface with thin easily detachable scales.

\section{others, in chronic brom} nervous system has to bear the main brunt of attack, yet the symptoms of bromism are not due to a surcharge by it of these centers, but rather of the blood. It replaces with avidity the chlorin content of the blood and the gastric juice and is found in the secretory and excretory organs. ${ }^{9}$

* Read before the Section on Dermatology at the Sixty-Fifth Annual Session of the American Medical Association, Atlantic City, N. J. June, 1914

1. Sharp: Pharm. Jour., 1911, xxxiii, 128.

2. Kross: Arch. f. exper. Path. u. Pharmakol., 1876, v, 6

3. Albertini: Arch. f. exper. Path. u. Pharmakol., 1882, xv, 248. 4. Nencki: Arch. f. exper. Path. u. Pharmakol., 1893, xxxiv, 313 5. Fell: Inaug. Diss. Wurzburg, 1899.

6. Hoppe: Neurol. Centralbl., 1906, xiv, 266; ibid, 1908, xliv, 186.

7. Von Wyss: Arch. f. exper. Path. u. Pharmako1., 1906, xlv, 266.

8. Ellinger: Arch. f. exper. Path. u. Pharmakol., 1911, 1xv, 87.

9. Ellinger: Med. klin., 1910, No. 38. 
It has been shown that those organs richest in chlorin contain the greatest amount of bromin, hence blood-serum contains the greatest amount of it, next in order being mother's milk, tears, saliva and the skin. In a regimen of salt-poor diet in animals Von Wyss has demonstrated that 40 per cent. of the chlorids must be replaced by bromids to cause poisoning, and Hoppe $^{10}$ found in the gastric secretions of epileptics one-third of the chlorids replaced by bromids when the bromin influence showed itself. The antagonistic effect of these two elements is remarkable. Bromism is caused by the accumulation of bromid-ions and diminution of chlorid-ions in the blood and in all the other body juices and organs. Both conditions, it seems, are interlocking; it may be the plus of bromin or the minus of chlorin that causes the intoxication. When table-salt is withheld from the diet of epileptics they become more susceptible to the action of bromin, while abundant administration of table-salt causes the bromism to disappear by increased kidney activity.

\section{ETIOLOGY OF DRUG ERUPTIONS}

These will be encountered chiefly in epileptics as they are the principal consumers of the bromin compounds. Though almost any drug may cause an eruption, yet, for obvious reasons, those caused by the.

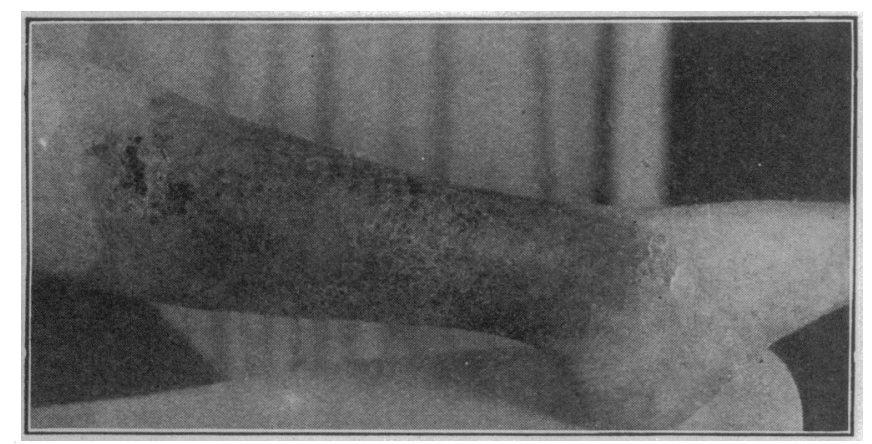

Fig. 2.-Bromoderma of leg; showing the convex lower border and centrifugal extension of the process downward. Outside aspect of right leg. Also shows some activity yet, as seen in the healing ulceration on leg. Also shows
the upper border.

iodids and bromids have merited the greatest attention by the profession. The mode of development of these eruptions has hitherto been quite conjectural, but certain observations have brought us nearer to concrete facts, although not to perfect understanding. There are several theories extant concerning the nature and manner of drug eruptions. It is somewhat disappointing that the most natural explanation, the excretion of the "materia peccans" by way of the blood through the glandular system of the skin, is doubted.

Not many facts resting on a solid basis have been adduced to prove modern and fanciful theories. Humoral pathology in modern garb, to which we unconsciously are drifting, offers a plausible explanation. If we substitute the modern toxin for the obsolete "materia peccans" and discard the mysterious "critical sweats and eruptions" by calling them reflex phenomena or vessel changes, then we have a working basis at least approximately serviceable to explain drug eruptions. The general consensus is to call drug eruptions only such phenomena of the skin as follow the ingestion and absorption of certain drugs. Skin lesions produced by the external application of drugs are called artificial dermatitis or dermatitis venenatae.

10. Hoppe: Neurol. Centralbl., 1906, No. 21.
Their action is due to their irritating properties exerted on the skin, which depend on the strength of the drug; while the drug exanthems per se do not generally depend on dosage. Here a predisposition, a so-called idiosyncrasy, must be present, an intolerance, as it were, for the particular drug or food (crabs, strawberries, etc.). But this arbitrary division becomes untenable when we consider that drugs like salicylic acid, antimony, chloral, antipyrin, etc., may cause eruptions when used both internally or externally; while others will not cause eruptions when applied externally, but will when taken internally (strophanthus, rhubarb, etc.). Again, iodoform is taken internally without unfavorable consequences, while externally it causes great irritation in some persons. It is, therefore, impossible to systematize the etiology of drug eruptions. They may be caused in different ways, either through irritation of the skin glands or their vessels in excreting the toxic substance, or through reflex irritation of the vessels. ${ }^{11}$

On the other hand, external skin irritants like rhus or chrysarobin may cause very intensive constitutional symptoms. The theory of cumulative action, while it fits certain phenomena, does not explain why certain individuals will show a skin eruption very soon after the ingestion of small quantities of a drug which does not harm the great majority of others. Such a predisposition may be a lasting or a temporary one, or one becomes accustomed to skin irritants. With quinin eruptions a hereditary predisposition is observed, while in some instances such abnormal sensitiveness may be acquired and in others become lost. Kaposi ${ }^{12}$ thinks that the vasomotor influence cannot hold good in all instances. Some rare cases of urticaria appear as soon as the provoking substance is taken into the mouth. Here the eruption can be explained only by a reflex irritation via the gustatory nerves.

Again the same drug may cause different forms of eruption in different individuals while different drugs will always cause the same form in the same person. ${ }^{13}$ The polymorphism of these drug eruptions is one of the main features distinguishing it from other welldefined inflammatory types which they may simulate and which are dependent on a functional disturbance of the vasomotor nerves (angioneuroses). . For instance, in urticaria $a b$ ingestis the toxins generated by the fermentative products from the gastro-intestinal canal act on the vasomotor centers in the same manner as the irritant drug iodin or bromin.

It is; therefore, as stated before, impossible to narrow down all the enunciations of drug exanthems into a system. Neither from the point of view of the drug, nor from that of the different response on the skin is such a generalization possible. We must have recourse to more or less proved theories, namely: an especially vulnerable skin, differences in the anatomic structures or their distribution (vessels, nerves), a peculiar receptivity of the system, deviation from the normal of the position of the skin-glands, secretory and excretory alterations of their functions and many other incidents partly speculative, partly scientifically demonstrable. Predisposition for and idiosyncrasy against a certain drug, food, or external irritant are yet valid as causes but fortunately not the exclusive explanations in this contradictory domain. If $\mathrm{I}$ add

11. Passini: Ann. de dermat. et de syph., 1906, vii.

12. Kaposi: Fathologie u. Therap. d. Hautkrankheiten, i, 238.

13. Joseph: Lehrbucl der Haut- und Geschlechtskrankheiten für Aerzte und Studierende, 1892, p. 120. 
to these more or less plausible theories that the skin lesions are catused by the drug itself or its metabolic changes directly or by reflex action via the vasomotor or trophic apparatus, we have in a nutshell all that is known of the causation of drug eruptions. ${ }^{14}$ Skin eruptions of a kindred type are observed also after adenoid operations, icterus, serum-therapy, etc.; here the trauma, the bile, the decomposed albuminous products are the causative agents of the skin eruptions.

SYMPTOMS, DIAGNOSIS AND PATHOLOGY OF BROMODERMA

The best evidence that drug eruptions are of angioneurotic character, caused by functional disturbances of vasomotor nerves, is the fact that they simulate almost to the point of confusion other well-known exanthems like erythema nodosum, erythema multiforme, urticaria, scarlatiniform eruptions, etc., known to be of angioneurotic origin; that fever and general systemic disturbances are mostly absent or when present appear only in a mild degree. This forms a distinctive point in the diagnosis of a drug eruption. The differentiation from the infectious angioneuroses-acute exanthems,-will not be a difficult task if we take into account their onset, development and the highly violent systemic disturbances accompanying them.

Iodin and bromin eruptions have some marked peculiarities which differentiate them from other medicinal skin lesions which show a tendency to appear either discrete or generalized. The two have very much in common and, in cases in which the vitiating drug is unknown, they may present some obstacles to a correct diagnosis. There are certain etiologic as well as clinical and histological features, however, which enable us to distinguish the one from the other in most instances.

The average bromin eruption, as is well known, starts with acne-like lesions in places where acne vulgaris usually appears. In its severer types the base of these papulopustules becomes infiltrated and the lesion appears to be raised above the surface. Soon others will appear and a patch of grouped pustular lesions clustered together become confluent in places, occupying a space the size of a silver dollar or larger. This type usually is found on the extremities, with a preference toward the lower one. This agglomeration is characteristic of bromid eruptions. Through proliferation and hyperplastic changes, tuberous, furuncular, and anthracoid formations develop which soon break down, forming fungating, papillomatous or ulcerated highly colored elevations, appearing as if a sarcoid had broken down. The borders of these elevations carry small, sieve-like perforations, giving it the appearance of a honeycomb, from which a foulsmelling smegma issues. These conglomerate patches soon become covered with greenish adherent crusts occupying large areas of several square inches, favor ing the lower part of the leg, as in the case I will describe; or they may appear in discrete patches all over the body. Phlyctenular eruptions of the conjunctiva bulbi, and furuncular lesions of the external auditory canal ${ }^{15}$ have also been observed. I have seen painful furuncles of the follicles of the vibrissae of the nostrils, causing an erysipeloid inflammation of

14. Compare Neuman: Lehrbuch d. Haut Krankheiten, French translation; Auspitz: System der Hautkrankheiten, Vienna, 1881; Crocker: Brit. Med. Jour., 1893, p. 1208; Szadeck: Zur Casuistik des Bromexanthems, Arch. f. Dermat. u. Syph., 1888, xx, 599; Besnier, Broecq and Jacques: La Practique Dermatologique, ii, 480

the alae nasi. Comby, ${ }^{16}$ Marzianni and others ${ }^{17}$ have seen in infants bromodermas acquired through their mother's milk.

The diagnosis of a bromin eruption, if the cause is unknown, may offer considerable difficulty. Diagnosis of the discrete, acne-like or the papulopustular form necessitates the knowledge of quite a goodly number of dermatoses which they resemble. Those which are ushered in as a generalized eruption will naturally make the diagnostician consider the possibility of one of the acute contagious exanthems, but fortunately there are distinguishing points from which one may arrive at a proper diagnosis. Common to all forms is the suddenness of outbreak and in the generalized forms the violence of development, both local and systemic; the brevity of the acute stage, and the relative quickness of defervescence. In the chronic conglomerated; fungating and exulcerating forms occupying at times almost the entire lower extremity, the risk of a faulty diagnosis is imminent, and sometimes fraught with grave danger to the patient. In the oft-cited case ${ }^{18}$

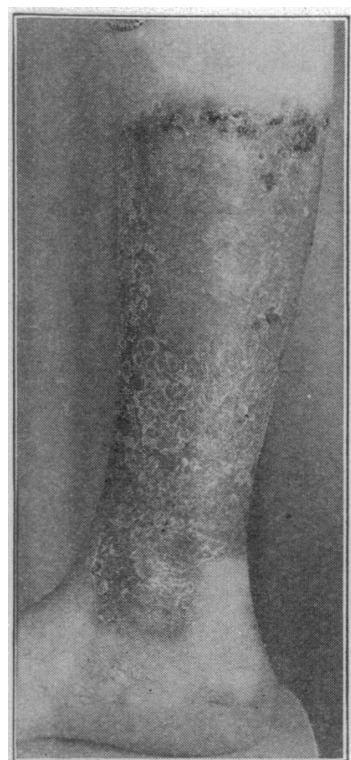

Fig. 3.-Inside aspect of right leg showing the same centrifugal extension as Figure 2. Note smooth atrophic scaly appearance.

that the process starts in the cutis vera in the form of minute abscesses. The coil-glands show changes, but the pilosebaceous glands are slightly and only secondarily involved. Hence they declare that the so-called bromid acne is not a real acne.

While Von Wyss and Ulrich ${ }^{22}$ consider local intolerance of the skin as the cause of bromid acne, Laudenheimer ${ }^{23}$ declares it to be a real symptom of bromin intoxication. According to Gley ${ }^{24}$ and Cannizarro ${ }^{25}$

16. Comby: Bromides cutanées chez les nourissons, Bull. Soc. de pédiat. de Paris, 1912, xiv, 153.

tuberoso osservato contemporane? mente nella madre e nel bambino lattante, Boll. d. Soc. med. di Parma 1912, Series 2, v, 53 .

Dermat. u. Syph., 1873, International Dermas. Cong., Vienna, 1892

von den Arznei-Auschlägen. Arch, f. Derm. u. Syph., 1894, v, 26 .

20. Guttman: Virchows Arch f path. Anat., 1888, 1xxiv, No. 4, p. 23 21. Fox and Gibbes: Brit. Med. Jour., 1885, 971

22. Von Wyss and Ulrich: Neurcl. Centralbl. 1910, 75

23. Laudenheimer: Zur Behandlung und Theorie des Bromismus, Neurol. Centralbl., 1910, lxxiv, 461.

24. Gley: Recherches sur le function de a glande thyroide, Arch e physiol. et de path, April, 1892.

25. Cannizarro: Dedtsch. med. Wichnschr., March 3, 1892. 
bromin has a vicarious action on the ganglia almost similar to the active principle of the thyroid gland. Its administration may cause hyperthyroidism.

\section{REPORT OF CASE}

History-A. L., aged 24, of healthy parentage, both parents living, had measles when 1 year old. At the age of 8 , she contracted scarlet fever, complicated with kidney trouble and convulsions. After recovery she remained quite well for a year, when the convulsions returned. From this time on she was subject to epileptic fits, against which the use of bromids was advised. One year after the use of the drugpotassium bromid-she had acne of the face and on the border line of the scalp, and soon the right leg became the seat of a papulovesicular eruption. In the beginning discrete, later these lesions through conglomeration became confluent, occupying the middle of the tibial region, and calf of the right leg. Considerable pain and impairment of locomotion was present. One of the peculiarities of the case consists in the strange phenomenon that the eruption becomes aggravated in the fall and winter, and assumes a milder aspect or complete

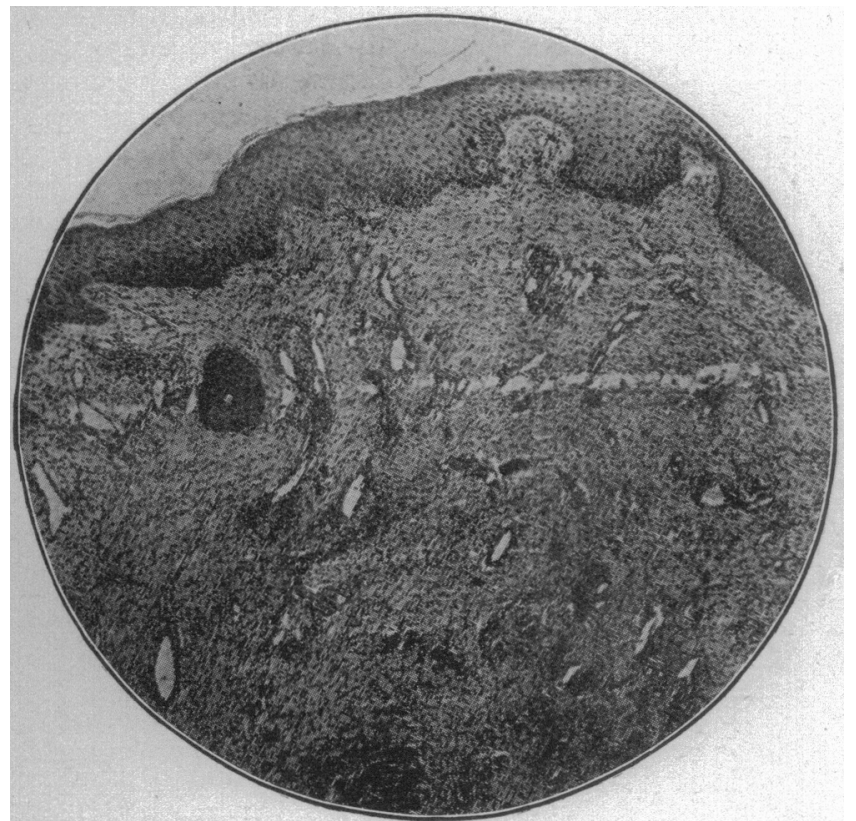

Fig. 4.-Bromoderma, showing partial obliteration of the papillary pegs. Spongiosis and intracellular edema. Dilation of lymph-spaces, moderate cell infiltration.

cessation in the spring. The patient denies a more abundant use of the bromid during the winter months, asserting that, in -order to avoid seizures, she uses the drug more frequently during the summer. She had no attacks for seven years. When she stopped taking bromid the attacks returned. The eruption, however, continued when medication was interrupted. For six years she has taken a patent medicine containing bromid and for the last two months she has stopped medication entirely with the result at present of the complete cessation of active skin lesions. When I first saw the patient three years ago, she had on her left leg a patch of aggregated papulopustules, on an infiltrated base about the size of her palm and covered with crusts. On the left upper thigh a fungating ulcer the size of a half-dollar was observable, which developed through the exulceration of several confluent lesions. It was very painful and bled at the slightest touch. This latter symptom will be dwelt on presently. The most interesting change occurred on the right lower limb. Here an inflamed surface presented itself, extending from the upper third cf the leg down to both malleoli. The front aspect (Fig. 1) shows a crusty, slightly-scalloped border studded with a few partly healed sallow ulcerations. The lower border ends abruptly in a semicircular concave line at about the crest of the tibia. The part which now presents a smooth atrophic surface covered with thin cigarette-paper-like easily detachable scales, in the active stage showed an oozing, ansrylooking surface, studded with innumerable pin-head- to splitpea-sized discrete and coalescing papulopustules considerably raised above the surface. The border of these papillomatous lesions had a honeycomb or sieve-like appearance from which a smegma-like offensive-smelling substance could be expressed. Some of these anthracoid and necrobiotic ulcerations as a remnant of former activity can yet be seen on the inner and outer border of the leg (Figs. 2 and 3). A most prominent feature, to my knowledge observed only once, though I have searched for it in the literature for the past thirty years, consists in a venous capillary hemorrhage from these ulcerations. At times, usually in the defervescing stage, a lamellous epidermic exfoliation would take place, exposing painful surfaces. Kudisch's case $^{20}$ resembles mine. It occupied three-quarters of the leg, had a vegetating appearance, bled easily, and had festooned borders. The hemorrhage, however, was not so abundant and there was no such epidermic exfoliation. My patient is not afflicted with hemophilia, has a normal blood-count, no nosebleed, no excessive menstruation and has healthy gums. At first varicose veins were thought of as the cause of this unusual symptom, but they were not found. Microscopic examination of an excised portion, however, revealed very marked dilatation of the blood- and lymph-vessels causing these extensive capillary hemorrhages in the pars papillaris. This finding explained the unusual feature of the lesion, caused by an excessive development of the vascular loops of the papillae, which formed the anatomic basis of the fungating lesion.

Histologic Examination.-By Dr. W. McMurtry of the Pathological Division of the Dermatological Department of the Vanderbilt-Clinic.

Epidermis: This shows considerable acanthosis. The interpapillary prolongations are shortened or absent generally. The rete malpighii is slightly edematous in spots and the intercellular spaces contain more than the usual number of leukocytes. In one area only, marked parakeratosis is seen, but elsewhere the stratum granulosum and corneum are approximately normal; the latter shows hyperkeratosis in certain areas although clinically a marked tendency to scaling was seen. Certain rete cells show intracellular edema while others are somewhat swollen and stain faintly.

Derma: The entire derma is markedly thickened. The hyperplasia is due partly to a swelling of the collagen, an increase in the connective-tissue cells, fixed and transitional, and to a very marked dilatation of both blood and lymphvessels and the presence around both of fairly dense cell infiltrations. The latter consists of some mononuclear and polynuclear leukocytes, a great many lymphocytes and a considerable number of plasma cells. Extensive capillary hemorrhages are noted in the pars papillaris. The walls of the larger blood-vessels show no evidences of degenerative changes. The elastic fibers are seen only in the deeper portion of the derma and appear thickened and broken. In the center of the sections there is an abscess. This has evidently begun as a follicular pustule and has then extended downward in an hour-glass shape. Surrounding it is a perifollicular infiltration of leukocytes, lymphocytes and connective cells with considerable number of red bloodcorpuscles. No giant cells and no chorioplaques were found. The sweat and sebaceous glands show periglandular infiltration. No evidence of either syphilis or tuberculosis is seen. Macrophage cells (Schaumzellen) as described by Passini ${ }^{27}$ were not found.

Figures 2 and 3 show the convex outline of the lower border of the lesions and the centrifugal extension of the process downward. It has not extended beyond this limit in the last two years, but shows some activity, as seen on the upper border. The photograph was taken in February and represents the usual, although at this time slight, winter exacerba-

26. Kudisch: Drei Fälle von Bromoderma Tuber. Veget., Dermat. Ztschr., 1912, p. 703 .

27. Passini: Pathology des eruptions bromides, Ann. de Dermatol. 1906, No. 7, p. 1 . 
tion. At present, in June, there are no ulcerations visible. The leg shows now a reddish-brown, smooth, slightly scaly, atrophic appearance. Its circumference is two inches less than the right one. The skin is tensely drawn and when pinched shows thin-ridged sallow papery folds. The whole process has lasted over three years. Bromids are taken and discontinued occasionally and for a short time. Bacterial cultures were negative, chemical analysis of sections also negative. The urine showed specific gravity of 1.013 , traces of albumin, a large excess of indican, subnormal excretion of urea, frequent crystals of calcium oxalate. No bromids were detected after careful search. This finding corresponds with the veracity of the patient with reference to the ingestion of bromids.

\section{DIFFERENTIAL DIAGNOSIS}

In the foregoing the confounding of medicinal eruptions with syphilis has been dwelt on as the most serious of possible mistakes. I will try to offer some points on differential diagnosis. The sudden onset and the usual topographic distribution of these eruptions should be constantly kept in mind. Thus, a pustular bromid acne will develop more acutely than a pustular syphilid. It will show a predilection for the head, face, and extremities, while the syphilitic eruption will be found irregularly scattered over the body though it adheres more or less to a symmetrical arrangement. Bromid acne extends down into the cutis and is harder to the touch than the syphilitic or necrotic variety. The absence of inflammation in acne cachecticorum will serve to distinguish it from bromid acne; and from acne vulgaris it can be differentiated by its rapid and simultaneous appearance on the scalp and other hairy parts, by the absence of seborrhea oleosa and comedones and of other concomitant signs of pilosebaceous gland alterations. Finally, bromid eruptions like to develop on scar tissue.

Acne caused by iodin has a more acute onset. Ehrman, ${ }^{28}$ however, classes it also with the bromid variety, while Szadeck attributes to the former a more acute beginning. I venture to remark that the affection of the mucous membranes as an almost always present symptom of iodin intoxication, will serve as an useful differential diagnostic sign. It should also be remembered that the iodin eruption shows a tendency to assume a bullous type.

To distinguish it from an exulcerated iododerma is at times very difficult. This develops from the bullous type, rarely observed in bromoderma and is accompanied by a highly inflamed, often erysipelatous, swelling, deeper necrobiosis and more intensive systemic disturbance. Moreover, it does rot occupy, as does the bromoderma, the lower extremities by predilection, and does not show the marginal honeycombed smegma-excreting walls. The examination of the urine and anamnesic data will also prove helpful toward a correct diagnosis.

Both the bromoderma and the iododerma offer at times insurmountable difficulties to differentiation from the exulcerated gummous syphilid. Both form ulcers by central breaking down; both show steep walls. The studded pustular points around the margin, the flabby, sluggish feel to the touch of the bromoderma, will vividly contrast with the gyrate serpiginous configuration and convex margin of the ulcerating tuberculosyphiloderm. The Wassermann reaction and, eventually, a provocative salvarsan injection will soon solve the question.

28. Ehrman: In Mracek's Handbuch der Hautkrankheiten, Vienna, 1891, part 3 , p. 505 .

\section{TREATMENT}

The antagonism between the two haloids, bromin and chlorin, one replacing the other and vice versa, has been utilized against bromin intoxication. Bromin retention in the system is due to ineffective kidney excretion. Bromin is absorbed quickly from the intestine, and if not excreted soon by the intestinal tract it rapidly manifests itself in the blood, deplacing its chlorids. It is, therefore, administered in cases of bromin intoxication in epileptics when untoward symptoms require cessation of the bromids. The same holds good in skin eruptions. Theoretically, the application of saline compresses on bromodermas and the ingestion of table-salt would recommend themselves. Ulrich $^{29}$ recommends also salt baths for the same reason. Ointments invariably aggravate the condition. In my case rest and a 4 per cent. boric acid solution applied continually and held in place by a soft gauze bandage kept moist, was very effective.

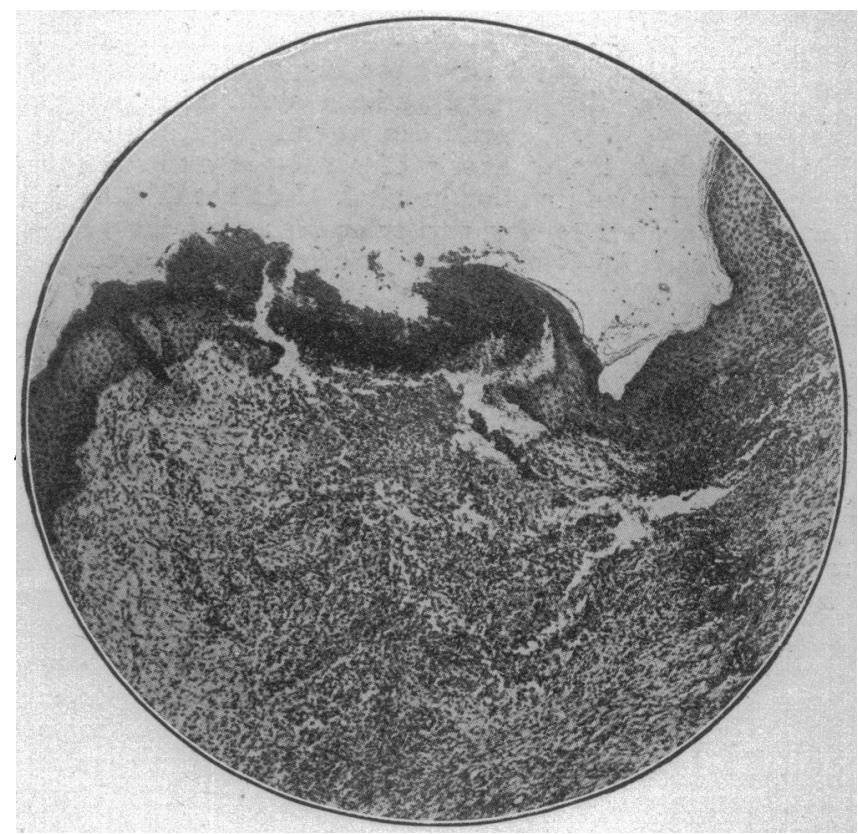

Fig. 5.-Bromoderma. Pustulation, atrophy of epidermis. Hemorrhage and round-cell infiltration.

\section{CONCLUSIONS}

1. Drug eruptions may simulate almost any known skin affection.

2. A skin eruption starting suddenly without any prodromal symptoms is almost sure to be a medicinal eruption.

3 . The violence of development, the preponderance of the local over the systemic disturbances is characteristic of drug eruptions.

4. The brevity of the acute stage and the quickness of defervescence constitute a notable asset in diagnosis.

5. The usual four stages of the actute contagious exanthems, namely, the prodromal stage, the eruptive, the fully developed and retrogressive and the desquamative stage are wanting.

6. The temperature never rises to the point shown by the acute exanthems and the affection of the mucous membrane is never so severe.

42 West Ninety-First Street.

29. Ulrich: München. med. Wchnschr., 1910, No. 22. 


\section{ABSTRACT OF DISCUSSION}

Dr. ERnest L. McEwen, Chicago: Cases of bromoderma are sometimes found in epileptics in which the skin eruption closely simulates blastomycosis. I recently saw a bromoderma in a girl of 16 , an epileptic, who for a long time had been taking large doses of bromids. The lesion in this case appeared suddenly and extended rapidly, totally unlike what we see in true blastomycosis. Dr. Oliver S. Ormsby of Chicago, reported a similar case some years ago, in which the lesion spread with astonishing rapidity and closely simulated blastomycosis.

DR. A. Ravogl, Cincinnati: Not long ago I saw a child with massive tumors on the face and head. The child had been treated with the Roentgen rays and was getting worse and the treatment had also set up a Roentgen dermatitis. On inquiry, it was learned that the child had been taking bromids, and when this was discontinued, the lesions healed under simple treatment. I have also seen an acneiform eruption on the legs, due to bromid which was very difficult to diagnose.

Dr. M. L. Ravitch, Louisville: I do not agree with Dr. Weiss that these cases are so very unusual; I think many cases of bromodermas have been reported in the literature, and $I$ have seen many cases more in private practice than in the asylums. The insane patients stand bromids better than normal people. I recall one case of bromoderma in an infant in which the diagnosis of small-pox was made and the child sent to an isolation hospital. I do not think lromoderma is confined to any particular season of the ycar. I have seen cases of bromoderma simulating blastomycosis, in winter, fall and summer.

Dr. George M. M.scKee, New York: I had the opportunity of studying this case very carefully, and it offered considerable difficulty in the diagnosis. Among other things, we considered tuberculosis, syphilis and blastomycosis, and finally arrived at the correct diagnosis by the process of elimination.

Dr. Ludwig WeIss, New York: Bromoderma is not a very rare condition, but in my case there were some unusual features. The hemorrhages from the vegetations were at times very profuse, owing to the dilated venous loops in the papillary layer. I mentioned the seasonal occurrence of bromoderma only as a curiosity. We find that erythema nodosum and other forms of erythema are worse in cold weather and improve in the summer. As Dr. MacKee has already pointed out, the lesions in this case had to be and were differentiated from a syphilid, pemphigus and other forms of eruption.

\section{FAVUS AND RINGWORM OF THE NAILS}

MILTON H. FOSTER, A.M., M.D. Surgeon, U. S. Public Health Service

\section{NEW YORK}

Favus and ringworm of the nails are supposed to be rather rare conditions. The finding of 101 such cases among the aliens arriving at Ellis Island during the first eight months of the present fiscal year goes to show that these disorders are probably more common, at least among our foreign population, than is generally believed.

Clinically both diseases present practically the same symptoms. The affected nail is thickened, brittle and sometimes even caseous. The natural color and transparency of the involved portion is lost and it becomes opaque and yellow or dirty-white in appearance. The process generally starts at the distal end and slowly infiltrates the nail toward the base, the diseased portion crumbling away gradually, because of the trauma to which the part is necessarily exposed in the ordinary vocations of life (Figs. 1, 2, 3, 4 and 5).
The side or base of the nail, however, may occasionally be first involved. Rarely the whole nail appears to be simultaneously attacked, and there is a more or less universal involvement of the whole horny substance. If the nail does not flake and break away, leaving a rough, uneven, diseased surface, it is very

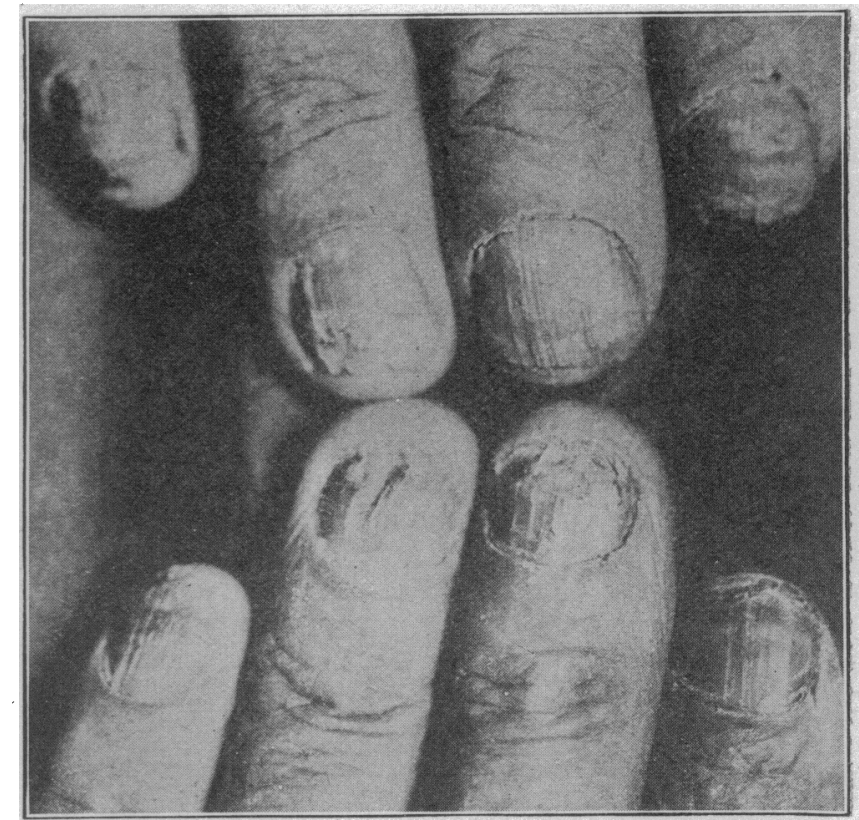

Fig. 1.-Ringworm of nails.

much thickened and deformed. Only one nail may be involved, or several or all. The thumb, index-finger and middle fingers are the ones most commonly attacked, and as the nails are generally infected from

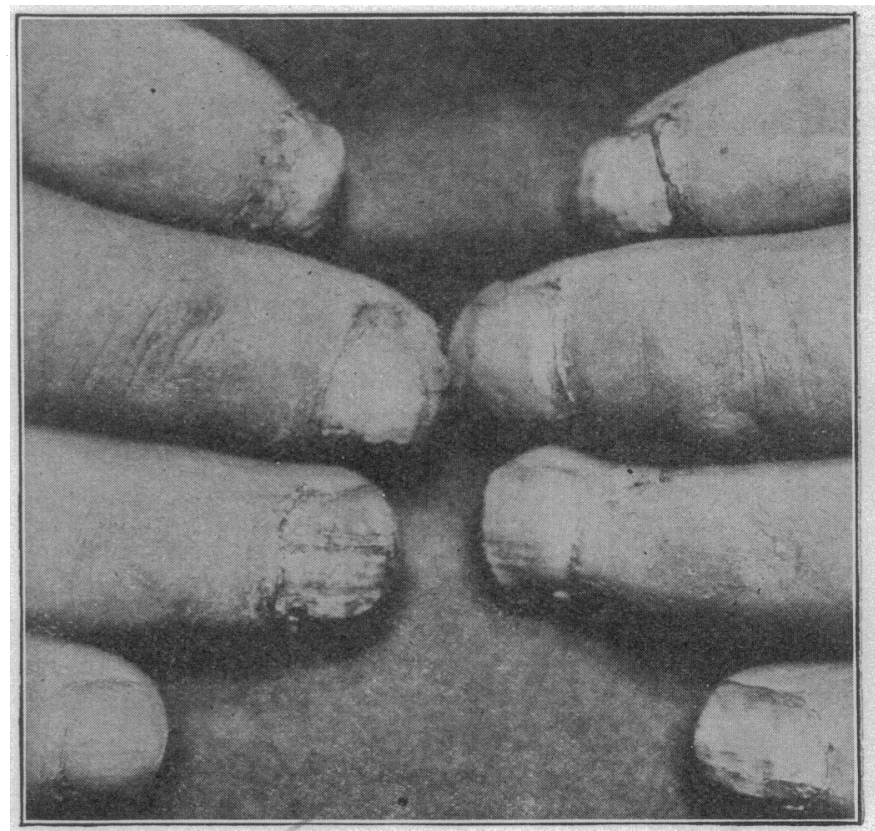

Fig. 2.-Favus of the nails.

scratching the scalp, this distribution would be expected.

The disease does not appear to be painful nor does it seem, at least in our experience, to predispose toward setting up any acute inflammatory conditions of the surrounding soft parts. 